\title{
Study on the Professional Quality of Pre-Outstanding Chemistry Teachers from the Perspective of Key Competence
}

\author{
Yiyan Su, Xiaohui Yang, Hongjiang Ren, Chengyin Yang*
}

School of Chemical Engineering, Xi'an University, Xi'an, 710065, China

syy5790@126.com, sheepyangxh@qq.com, hjren@xawl.edu.cn, *yangcy@snnu.edu.cn

\begin{abstract}
Current wave of key competence and core literacy brought the age of education reform which put forward new requirements to the professional qualification, and the pre service outstanding chemistry teachers is the backbone for the future to create outstanding middle school chemistry teachers. To improve the middle school chemistry teacher's professional level and the quality of education, we must first cultivate a group qualified pre service chemistry outstanding teachers. By reading and analyzing the related literature, this paper expounds the professionalism of pre-service outstanding chemistry teachers from three aspects: advanced educational theories, noble morality, comprehensive professional knowledge structure and solid professional ability, in order to provide the basis for the development of personal chemistry and curriculum for outstanding chemistry teachers.
\end{abstract}

Keywords: key competence; pre-service teacher; outstanding chemistry teacher; professional accomplishment.

\section{职前卓越化学教师核心素养下的专业素养探讨}

\section{苏毅严，杨晓慧，任宏江，杨承印}

西安文理学院 化学工程学院, 陕西西安 中国

摘 要: 学生核心素养以及学科核心素养的提出对中学化学教师的专业素养发展提出了新的要 求, 而职前卓越化学教师是为今后打造优秀中学化学教师队伍的中坚力量。要提高中学化学 教师的专业化水平, 提高教育质量, 首先就要培养一批合格的职前卓越化学教师。本文通过 阅读及分析相关文献, 对职前卓越化学教师的专业素养从先进的教育理念和高尚的道德、宽 厚的专业知识结构、扎实的专业能力三方面进行了阐述, 以期为职前卓越化学教师个人专业 发展及课程设置提供依据。

关键词：核心素养;职前教师;卓越化学教师;专业素养.

\section{1. 研究背景}

\section{1. 学生核心素养的背景}

1997年底，经济合作与发展组织（OECD）启动 “素养的界定与遴选（DeSeCO）：理论和概念 基础” 项目，提出 “核心素养” 的概念，基于 “成功的生活和健全的社会” 这一观念，确定 与选择了三大类核心素养：互动地运用工具 ( 如语言、技术) 、与异质群体互动、自主地行 动 [1]。自此, 世界各国基于自己的教育实际和基本国情, 制定和颁布了诸多有关核心素养 的政策文件，分别对核心素养进行了概念界定和内容选择，例如联合国教科文组织提出的 “五 大支柱说” ，美国提出的 “ 21 世纪关键能力” 等。习近平总书记在党的十八大报告中提出 “把 立德树人作为教育的根本任务”。2018年9月10日又提出德智体美劳五育并重的培养目标。2014 年教育部颁布《关于全面深化课程改革，落实立德树人根本任务的意见》中曾多次提到 “核 心素养或素养”，这意味着党和国家将 “核心素养” 问题的研究放在了一个前所未有的高度 [2], 我国前教育部部长委托北京师范大学着手中国学生发展核心素养的课题研究, 林崇德及 其团队自2013年到2016年9月开始，历时3年多，完成了《中国学生发展核心素养（征求意见 
稿）》, 该意见稿对 “我国学生核心素养” 进行了定义: 学生发展核心素养, 主要是指学生 应具备的, 能够适应终身发展和社会需要的必备品格和关键能力 [3]。

\section{2. 化学学科核心素养的背景}

教育部2014年 “立德树人” 文件的颁布，习近平总书记2018年9月10日提出德智体美劳全面发 展培养目标, 使学生核心素养及各学科核心素养的关注达到了热点。需要注意的是, 学科核 心素养不能等同于学生核心素养, 邵朝友等人将核心素养定义为 “通过学习某学科的知识与 技能, 思想与方法而习得的重要观念、关键能力与必备品格” [4]。福建师大余文森教授认为: 学科核心素养是学科本质观和学科教育价值观的反映, 只有抓住学科核心素养, 才能抓住学 科的根本, 学科核心素养是学科和教育的有机融合, 学科核心素养的提出意味着教育模式及 学习方式的根本改变 [5]。本文比较认同的观点是, 学科核心素养是核心素养与学科教育实 践的纽带, 学科核心素养是对某些特定的素养的培养, 对学生核心素养的培养有一定的个性 价值，但是不完全等同于学生核心素养。

一所学校教学质量的高与低, 最重要的要素还是要看教师。高水平的教师, 是一所优质学校 的基本保证, 教师的专业化水平决定着教育的效能和质量, 决定着新课程改革的成败 [6]。在 教师教育不断发展的过程中, 卓越教师的培养为教师的专业发展指明了方向, 并成为国际教 师教育的普遍共识。在化学学科的教学中, 要想更好地培养学生的化学学科素养, 就需要建 设高质量的化学教师队伍, 而职前卓越化学教师是高质量的中学化学教师的潜在力量。

\section{2. 职前卓越化学教师应具备的专业素养}

教师在教育活动中扮演着极其重要的角色, 而教师的特殊性在于, 他们要面对有思想并处于 不断发展和变化过程中的学生, 所以教师专业素养的要求也与其他职业素养有所不同。林崇 德等人认为, 教师素质在结构上, 至少应包括职业理想、知识水平、教育观念、教学监控能 力以及教学行为与策略 [7]。叶澜教授领衔的团队研究认为, 我国教师专业素养主要体现在 4 个方面: 教育理念、专业知识、专业能力与教育智慧 [8]。石中英教授提到, 卓越教师的专业 素养是指 “卓越教师” 专业的态度、专业的知识、专业的精神和信念 [9]。英、美、德、澳等 发达国家在推进卓越教师培养方面积累了丰富的经验, 对我国的卓越教师培养计划有很大的 启示和借鉴作用 [10], 2011年, 我国教育部颁布的《中学教师专业标准 (试行)》列出专业理 念与师德、专业知识、专业能力三大维度。基于以上不同学者的观点, 笔者认为可以将职前 卓越化学教师的专业素养分为以下三个方面。

\section{1 . 先进的教育理念和高尚的道德}

教师作为人类心灵的工程师, 对于培养什么样的学生及如何培养学生要有一个正确的认识与 理解; 为人师者必须要具备良好的道德修养, 真正做到为人师表, 因此教师具备正确的、先 进的教育理念及高尚的道德对于成为优秀的教师具有十分重要的意义。

\section{1. 1. 正确而先进的教育理念}

理念是对某一事物的观点、看法、信念, 没有正确的理念就不可能有正确的方法 [11]。教师 的教育理念主要是在认识基础教育的未来性、生命性和社会性的基础上，形成新的教育观、 学生观和教育活动观 [12]。本文认为教育理念是指教师在对教育工作本质理解基础上形成的 关于教育的观念和理性信念。有没有对自己所从事职业的理念, 是专业人员与非专业人员的 重要差别, 也是教师专业素养不同于以往对教师的要求的重要方面。

教师是 21 世纪核心素养能否在课程、学与教、评价中真正得到落实的关键影响因素, 许多国 际组织与经济体针对基于 21 世纪核心素养的教师专业化发展进行了设计与实践尝试 [13], 而 化学课程标准是规定化学学科的课程性质、课程目标、内容目标、实施建议的指导性文件, 
余文森教授提到学科核心素养使课程标准的形态从教学大纲 (双基)、内容标准 (三维目标) 走 向成就标准 (核心素养), 即以学生应该达到的素养 (成就) 作为课程标准的纲领 [14]。这个观 点对于化学学科依然适用, 新的化学课程标准也是将以化学学科核心素养为指导进行编制, 即学生应达到的素养 (成就) 作为化学课程标准的纲领。因此, 对于还未走上教育岗位的化 学师范生来说, 能否理解和消化 21 世纪核心素养, 能否正确解读化学学科核心素养及相关文 件, 是成为教师以后能否较好地践行教育政策及教育理念的关键所在。对于中学化学教师来 说, 只有掌握了正确的教育理念, 才能根据教学实际找到合适的教学方法, 从而进行高效的 教学。

\section{1. 2. 高尚的道德}

柏拉图曾经说过, 教育是一种灵魂转向的艺术 [15]。教师对于学生来说, 既是心灵的指导者, 也是人格构建的帮助者, 教师的道德水平对于培养学生的完美人格、道德情操起着至关重要 的作用, 因此高尚的道德是职前卓越化学教师未来能否做好教育工作的重要条件。苏格拉底 认为, 认识自己就是道德, 在研究自我心灵的过程中, 就能探索真理, 寻找最美的善 [16]。 因此要想成为德道高尚的中学化学教师首先要有一个正确的自我认识, 正确定位自己, 才能 不断成长与进步。学高为师, 身正为范, 教师的职业道德素质和人格品质对教育是十分重要的。 高尚的道德是教师必备的职业品质，是做好教育工作不可缺少的重要条件。

在21世纪核心素养及化学学科核心素养的大背景下, 职前卓越化学教师要能够正确地认识自 己, 具备强烈的自我意识及自我专业发展的意识, 也要善于学习, 教师作为学习者对于核心 素养相关文件的解读越到位, 那么学生获得 21 世纪核心素养或者化学学科素养的成效就越显 著中学化学教师肩负对学生化学核心素养及化学学科核心素养启蒙的重任, 在化学教学中, 教师要将自己的道德理念传递给学生, 而不仅仅是对学生进行知识与能力的传递, 只有具有 良好的道德修养的教师，才可能教导出高素质高道德水平的高素质学生。

\section{2. 宽厚的专业知识结构}

教师在对自己所教学科的知识的掌握要全面而系统的基础上, 对其他学科也要有所涉猎作为 中学化学教师, 也应该树立活到老学到老的理念, 要不断的提高自己的素质修养, 也要随着 时代的发展进步不断更新自己的知识储备, 不能拘泥于已经掌握的知识, 知识并不是一层不 变的, 而是不断更新的, 不同类别的教师在特定专业知识与能力上有显著性差异, 教师对自 身的发展学习更注重时效性 [17]。对于中学化学教师, 除了要掌握系统全面的化学专业知识 和过硬的化学实验基本技能之外, 还要具备其他与化学相近自然学科 (如物理、生物等学科) 等的基础知识, 人文素养也是作为一名理科教师必不可少的。另外, 在化学教学中保证教学 内容的科学性, 是提高学生化学核心素养的重要前提条件, 这就意味着职前卓越化学教师必 须保证自己的教学中不出现科学性错误。

基于以上背景, 对职前卓越化学教师最基本的要求就是要掌握合理的知识结构, 首先是对于 化学学科的知识要有一个系统全面的认识, 既要知其然, 也要知其所以然, 不仅仅要对中学 化学十分熟悉, 也要对大学期间学过的化学知识有足够的掌握、积累和深入的了解。对中学 化学的各个版本的教材及内容都能清楚它们的知识脉络; 不仅仅需要掌握化学学科的知识, 还需要对与化学相关和相近的专业知识有所涉猎; 再者还需要关注化学学科及化学教育研究 的前沿动向, 关注最新的研究成果。化学教师还需要具备一定的人文知识素养, 一位教师在 课堂上若能将化学与人文穿插着讲给学生, 那么对于吸引学生的注意力有很大帮助。教师拥 有丰富的人文知识, 具有人文情怀, 在与学生的交往过程中或教学过程中, 更加容易与学生 产生共鸣, 有助于课堂教学更加有效的进行。 


\section{3. 扎实的专业能力}

职前卓越化学教师应具备扎实的专业技能, 并能够创造性的教学, 还要具备熟练的实验技能 和一定的教育研究能力, 掌握一定的教育知识与规律, 能够使用合理的科学研究方法, 能够 对所从事的教育工作进行相关研究等。

\subsection{1. 专业教学能力}

教学技能既是教师素质的基本要求, 也是实际教学中不可或缺的因素。教师教学技能的提高, 既有助于提高教师专业素养和教学质量, 又有助于学生良好素养的形。对于职前卓越化学教 师来说, 良好的教学技能是作为一名优秀的中学化学教师的基础, 具备良好的教学技能, 能 够很好的将课程标准与教材整合到一起, 学会设计符合学生学情的教学设计, 并能够很好的 设定教学目标, 掌握并突破教学重难点。此外教师的语言是否规范、教学体态语是否得当等, 也是教师是否具有良好的专业技能的体现。化学教师担负着学生化学学习的启蒙重任, 在教 学语言上必须规范, 这样有利于帮助学生养成良好的化学用语习惯。

随着时代的发展, 现代教育技术发展迅速, 多媒体教学的手段早已应用到了教学中, 类似于 翻转课堂, 智慧课堂等也早已用在教学实践当中, 职前卓越教师也要掌握一定的现代教育技 术应用能力, 将教育技术与实际教学相结合, 从而促进教学的有效性。

\subsection{2. 熟练的实验技能}

化学是一门以实验为基础的自然学科, 也可以说, 实验是化学的灵魂, 对于职前卓越化学教 师来说, 严谨科学的实验态度, 规范、娴熟的操作技能是最基本的实验素养的要求。熟练的 化学实验操作技能无疑是必不可少的, 尤其是演示实验, 对于化学教师的要求则是只许成功不 许失败, 这就对教师的实验技能提出了一定的要求, 不仅要会做实验, 也要会解释实验现象、 总结实验背后隐藏的规律, 引导学生能够透过现象看本质, 教会学生用宏观和微观的视角去 认识事物。职前卓越化学教师要能够对实验进行创造性教学, 采用科学探究的方式进行教学, 对中学化学实验中已有的实验, 进行科学合理的改进, 可以有效激发学生对学习化学的兴趣 的欲望, 同时通过引导学生通过生活中的日常生活用品进行家庭小实验, 有助于学生学以致 用, 活学活用, 让学生知道化学是与生活息息相关的, 而不仅仅是抽象出来的只存在于书本 上的知识。

\section{3. 3. 教育科研能力}

教育科研能力是一种高级的、来源于教育实践又超越教育实践本身的创新能力。以教育科研 为依托, 以科研促教育教学, 积极开展教育教学改革的实验研究是提高教师专业化水平的重 要途径, 明确的教育反思意识和较强的教育研究能力是每一个追求卓越的化学教师都应该具 备的 基本素质。职前教育阶段应该为卓越化学教师获得这种素质提供理论基础和初步的实践 经验 [18]。职前卓越化学教师要有积极主动地承担起有关中学化学教育教学的相关研究课题 的意识, 通过研究课题, 提高自己的专业化发展水平和学术水平, 开阔教育教学视野, 发现 教育教学改革的新途径; 通过课题研究, 职前化学教师也能提高自己的研究能力, 增强自己 教育教学的责任感、使命感和自豪感, 也能激发教师的教育热情。

\section{3. 结语}

职前卓越化学教师是未来中学化学教师队伍的中坚力量, 职前卓越化学教师专业素养水平的 高低, 直接影响着今后化学教育的发展及对学生化学学科核心素养及核心素养培育工作的进 展。教师工作的独特之处就在于教师本身需要对教育理念、道德水平、知识结构的不断更新、 教学科研等能力的不断提高, 并且要不断地超越自我, 更新观念、不断提高和完善综合素质, 教师的专业素养是处在逐渐发展的状态, 处于不同阶段的教师, 专业水平是有差别的, 不能 
以统一的标准来衡量职前卓越化学教师和在职化学教师, 因此, 关于职前卓越化学教师的专 业素养的探讨及研究亟待补充和完善。

\section{References}

[1]. OECD. (2005).The Definition and Selection of Key Competencies: Executive Summary, 4.

[2]. Chongde Lin. (2016). Research on the Core Literacy of Students in the 21st Century. Beijing: Beijing Normal University Press, 2.

[3]. Research Group on Core Literacy. (2016). Chinese Students' Development Core Literacy. Journal of The Chinese Society of Education, 10, 1-3.

[4]. Zhaoyou Shao, Wenye Zhou \&Yunhuo Cui. (2015). The Development of Curriculum Standards Based on Key Competencies: International Experience and Enlightenment. Global Education, $08,10-24$.

[5]. Wensen Yu. (2016). From Three-dimensional Objectives to Core Literacy. Journal of East China Normal University(Educational Sciences), 01, 11-13.

[6]. Tiefang Liu. (2004). Watch Education. Shanghai: East China Normal University Press, 25.

[7]. Chongde Lin, Jiliang Sheng \& Tao Xin. (1996). Composition of Teachers' Qualities and Ways to Cultivate them. Journal of The Chinese Society of Education, 06, 16-22.

[8]. Lan Ye. (1998). On Teachers' Professional Attainment for New Century. Educational Research and Experiments, 01, 41-46.

[9]. Zhongying Shi. (2008).Prepare to Be An Outstanding Teacher. Teachers Journal, 23, 5-6.

[10]. Yifei Ma. (2014).The Outstanding Orientation of International Teacher Education Reform: A Case Study of Outstanding Teacher Training Programs in Britain, America, Germany and Australia. Journal of World Education, 08, 29-33.

[11]. Rongsheng Huang et al. (2014). New Theory on Teachers' Professional Ethics. Beijing: People's Education Press, 144.

[12]. Hui Zhang. (2007). Research on the Development of Chemistry Teachers' Professional Literacy under the New Curriculum Idea. Beijing: Capital Normal University.

[13]. Rui Wei \& Sheng Liu. (2016). Supporting 21st Century Competencies Education. Journal of East China Normal University (Educational Science Edition), 03, 46-51.

[14]. Zhi Qi. (2012). Strip off the responsibility of education. Nanjing: Jiangsu Education Press, 51.

[15]. Wenjin Cheng. (2012). Self-education in the Perspective of Management. Beijing: Central Compilation \& Translation Press, 6-68.

[16]. Chengyin Yang \& Jiaorong Yang. (2013). Research on the Science Teachers' Professional Development Status and Its Countermeasures: A Case Study of Middle School Chemistry Teachers in Shaanxi Province. Contemporary Teacher Education, 01, 31-36.

[17]. Chengyin Yang \& Shuangjun Gao. (2016).Curriculum Setting of Pre-service Teacher Education for Training Outstanding Chemistry Teacher.Chinese Journal of Chemical Education, 10, 44-48. 